\title{
DINAMIZANDO E MOTIVANDO O APRENDIZADO ESCOLAR POR MEIO DOS JOGOS PEDAGÓGICOS
}

\author{
F. M. BRITO, M. G. SÃO-JOSÉ, F. B. TERESA e L. S. ONDEI \\ Universidade Estadual de Goiás \\ luondei@yahoo.com.br*
}

Artigo submetido em setembro/2013 e aceito em abril/2015

DOI: $10.15628 /$ holos.2015.1623

\section{RESUMO}

Este estudo objetivou avaliar a eficiência dos jogos pedagógicos para a aprendizagem e o interesse promovido pelo seu uso por meio de uma abordagem experimental. Alunos do Ensino Fundamental $(n=72)$ foram submetidos a um dos três tipos de aulas (tratamentos): (i) aula tradicional; (ii) aula tradicional e aplicação do jogo; (iii) somente aplicação do jogo. Verificou-se que a sala submetida à aula e ao jogo apresentou maior aprendizagem em relação às demais $(p<0,04)$, não havendo diferença entre as salas que tiveram somente a aula tradicional ou somente o jogo $(p=0,77)$. Em uma avaliação da percepção dos alunos com relação ao uso do jogo evidenciou que $82 \%$ dos respondentes consideraram as aulas com o uso dos jogos mais atrativas e motivadoras. Desta forma, os resultados evidenciam que, quando combinadas com metodologias tradicionais, as técnicas de ensino/aprendizagem lúdicas podem gerar resultados mais satisfatórios de aprendizagem.

PALAVRAS-CHAVE: Lúdico. Didática. Aula. Motivação

\section{IMPROVING AND MOTIVATING THE SCHOLAR LEARNING THROUGH EDUCATIONAL GAMES}

\begin{abstract}
The efficiency of educational games for improving student learning and interest in classes were evaluated by using an experimental approach. Students from the primary level of education $(n=72)$ were submitted to one of the three types of classes (experimental treatments): (i) a traditional class, (ii) a traditional class followed by the use of educational game; (iii) educational game only. The students submitted to the traditional class followed by the use of educational game presented a higher learning gain compared with other treatments $(p<0.04)$.
\end{abstract}

Furthermore, there was no difference in the learning gain between students from the other treatments $(p=0.77)$. An evaluation of the perception of the students regarding the educational game revealed that $82 \%$ of them found the class more attractive and motivating when the educational game was used. The results highlight that, when combined with traditional methodologies, the recreational techniques can produce more satisfactory learning results.

KEYWORDS: Ludic. Didactic. Class. Motivation 


\section{INTRODUÇÃO}

O interesse e a participação dos alunos em sala de aula é um tema que desperta grandes preocupações e debates. É notório que os alunos que frequentam as escolas atualmente estão alicerçados em um mundo muito mais avançado tecnologicamente e o acesso à informação vai além de livros e enfoques familiares. No contexto atual, as crianças obtêm acesso a ambientes projetados com diferentes mídias que fascinam e encantam, despertando nelas graus de atratividade elevadas. Ao chegar à escola, o aluno espera do educador a adequação do ambiente escolar. Nesse contexto, não basta aos professores o domínio de conteúdo, sendo necessária também a utilização de abordagens alternativas para a construção do conhecimento (KNÜPPE, 2006).

Meirieu (2005) observou que toda aprendizagem verdadeira requer a mobilização do interesse do aluno, porém a grande discussão é como os educadores podem construir uma ponte entre o interesse do aluno e o saber que lhe é necessário. Para isso, a adequação do ambiente escolar ao interesse do educando para que ele se sinta disposto a expressar sua opinião e agregar conhecimento, é imprescindível. Isso pode ser representado pela busca por novos métodos de ensino que despertem o interesse dos alunos e facilite o processo de ensino-aprendizagem. Nesse contexto, os recursos didáticos alternativos e as atividades lúdicas estão sendo cada vez mais desenvolvidas e utilizadas (PEDROSO, 2008; CANTO; ZACARIAS, 2009). Para serem lúdicas, as atividades devem ser prazerosas e desafiadoras; criar possibilidades ou disporem delas; possuir dimensão simbólica, quando há uma relação entre a pessoa que faz e aquilo que é feito ou pensado; expressar-se de modo construtivo ou relacional (MACEDO; PETTY; PASSOS, 2005).

Um dos recursos didáticos alternativos que se enquadra no contexto descrito acima é representado pelos jogos pedagógicos. De acordo com Prieto e Figueroa (1984), os jogos pedagógicos são elaborados para estimular as funções mentais de forma generalizada ou de forma específica. De maneira geral, os jogos pedagógicos ou educativos são importantes ferramentas lúdicas, pois possuem boa aceitação e estimulam o dinamismo, motivação, competitividade e estratégia, sendo, portanto, capazes de unir o cotidiano escolar a diferentes aspectos comportamentais (CASTOLDI; POLINARSKI, 2009). Além disso, os jogos também representam um grande estimulador do raciocínio, auxiliador do processo de ensinoaprendizagem (GRÜBEL; BEZ, 2006). Por meio do lúdico, tanto a criança quanto o adolescente são livres para determinar suas ações e o contato com um material variado, desperta o desejo de realizar uma série de atividades. Ao identificar esse desejo, o professor deve então tentar enriquecer e problematizar a atividade para que os estudantes não participem mecanicamente (SILVA; METTRAU; BARRETO, 2007).

Apesar do uso de jogos pedagógicos nas escolas estar previsto nos Parâmetros Curriculares Nacionais (MINISTÉRIO DA EDUCAÇÃO, 2006), eles não são unanimidade entre os professores que, muitas vezes, os veem como diversão e não como uma atividade associada ao processo de ensino-aprendizagem. É verídico que quando o jogo é mal elaborado e/ou executado, os resultados podem não ser satisfatórios para o ensino-aprendizagem, tornando-se meramente um passatempo (ALMEIDA, 2003). Nesse sentido, para que a sua utilização seja fundamentada e os seus benefícios potenciais concretizados, é fundamental que a sua efetividade seja devidamente avaliada. Neste estudo, avaliamos experimentalmente, de forma 
quantitativa a efetividade da aplicação de jogos pedagógicos como uma metodologia alternativa de ensino-aprendizagem.

Assim, o presente estudo objetivou avaliar o potencial dos jogos pedagógicos como ferramenta de ensino-aprendizagem. Para isso, foi desenvolvido um jogo relacionado com o conteúdo de ciências para ser aplicado em salas do Ensino Fundamental e a sua eficiência foi avaliada por meio da verificação de aprendizagem dos alunos submetidos a diferentes tratamentos, incluindo o uso do jogo e de aulas expositivas tradicionais. Complementarmente, o interesse e a percepção dos alunos com relação à aplicação do jogo também foram avaliados.

\section{MATERIAL E MÉTODOS}

\subsection{Local do estudo e confecção do jogo}

O estudo foi realizado em uma Escola Municipal de Santa Tereza de Goiás/GO. Utilizaramse como sujeitos da pesquisa, 72 alunos do Ensino Fundamental II, distribuídos em três turmas de 24 alunos cada, sendo duas do sexto ano e uma do sétimo ano.

Inicialmente desenvolveu-se o jogo "Biomas do Brasil", composto por um tabuleiro (dimensão $60 \mathrm{~cm} \times 60 \mathrm{~cm}$ ) no qual foi impresso o mapa do Brasil com suas divisões por biomas; 32 cartas (dimensão $5 \mathrm{~cm} \times 5 \mathrm{~cm}$ ), sendo seis com os nomes dos biomas e 26 com fotos referentes à exemplares da fauna e da flora típicos de cada bioma, destacando suas principais características; e um roteiro explicativo com as orientações de como jogar. Foram confeccionados dois jogos idênticos para serem utilizados simultaneamente, a fim de que a turma pudesse ser dividida em grupos de no máximo 15 participantes, assumindo que a aplicação do jogo em grupos mais numerosos poderia resultar em uma menor participação de alguns alunos. Desta forma, para a execução do jogo, a turma foi dividida em duas equipes, uma para cada exemplar do jogo.

Para desenvolver a tarefa, os alunos deveriam completar o mapa do Brasil colando o nome dos biomas na região correspondente do tabuleiro e, em seguida, colar as figuras representando a fauna e a flora típica do respectivo bioma. As cartas só podiam ser coladas com o consentimento da maioria dos participantes e o tempo deveria ser respeitado por ambas as equipes. Posteriormente, o docente devia fazer a correção das cartas adicionadas ao tabuleiro na presença de todos os alunos, mostrando e pontuando os acertos e esclarecendo os erros, tornando este momento uma boa oportunidade de esclarecer as dúvidas da turma. A equipe que obtivesse mais pontos ao final, era a ganhadora. O jogo foi aplicado com a supervisão de um professor que interagiu com os alunos fomentando a discussão sobre o tema e a troca de informações.

\subsection{Delineamento experimental}

O delineamento experimental utilizado na presente pesquisa foi o quase-experimental e consistiu na aplicação de um teste de conhecimentos antes e após a aplicação dos tratamentos. Para a avaliação da efetividade do jogo, cada turma foi submetida a um tratamento experimental. $O$ tratamento AULA consistiu na realização de uma aula tradicional expositiva sobre o tema Biomas do Brasil (sala 1). O tratamento AULA+JOGO consistiu na apresentação da 
aula tradicional e a aplicação do jogo após a aula expositiva (sala 2). O tratamento JOGO consistiu somente na aplicação do jogo, sem que a aula expositiva fosse ministrada (sala 3). Em seguida, o questionário foi novamente aplicado. As aulas expositivas tiveram o mesmo tempo de duração (45 minutos), foram ministradas pelo mesmo professor, com o uso do quadro negro e giz. As duas turmas, em que foi aplicado o jogo, foram submetidas às mesmas regras com o auxílio do mesmo professor durante o mesmo período de tempo (25 minutos).

Antes e após a aplicação de cada um dos tratamentos, os alunos responderam a um questionário com sete questões de múltipla escolha, visando avaliar o seu grau de conhecimento sobre o tema. A correção dos questionários ocorreu após a aplicação dos tratamentos, tendo sido atribuídas notas em uma escala de 0 a 100, de acordo com o número de acertos. A partir das notas obtidas em ambos os questionários, calculou-se, para cada aluno, a diferença entre a nota obtida após o tratamento e a nota obtida antes do tratamento, a qual representou o ganho de conhecimento de cada aluno. Esse procedimento possibilitou a comparação da aprendizagem pelos alunos entre os tratamentos, independentemente do conhecimento prévio que possuíam e das diferenças intrínsecas a cada turma.

\subsection{Avaliação da percepção e aceitação do jogo}

Com a finalidade de aprofundar na avaliação da opinião dos estudantes sobre a aplicação dos jogos e para complementar os resultados da abordagem experimental descrita acima, foi realizada uma avaliação qualitativa. Para isso, foi aplicado um segundo questionário composto por sete perguntas abertas, explorando aspectos relacionados ao interesse e à motivação dos alunos em relação aos modelos de aulas apresentadas. Essa avaliação ocorreu somente na turma que foi submetida ao tratamento AULA+JOGO, uma vez que puderam experimentar ambas as metodologias.

\subsection{Análises estatísticas}

O ganho de conhecimento, representado pela diferença entre a nota obtida após o tratamento e a nota obtida antes do tratamento (ganho de aprendizagem) por cada aluno, foi comparado entre os tratamentos por meio da Análise de Variância (ANOVA), complementada pelo teste post-hoc de Fisher LSD. O nível de significância adotado foi de $5 \%(p<0,05)$.

\section{RESULTADOS}

Verificou-se que os alunos submetidos ao tratamento AULA+JOGO obtiveram maior ganho de aprendizagem em relação aos alunos dos demais tratamentos $(p<0,04)$. Além disso, os alunos submetidos aos tratamentos AULA e JOGO não diferiram entre si com relação ao ganho de aprendizagem $(p=0,77)$ (Figura 1$)$.

Na sala em que foi aplicada somente a aula tradicional, com o uso do quadro e do giz verificou-se que os alunos permaneceram dispersos e solicitaram autorização para se ausentarem diversas vezes, além de engajarem em conversas paralelas. Por outro lado, foi fácil controlar o tom de voz e o movimento da turma. Já na sala em que foi utilizado somente o jogo, os discentes ficaram agitados, eufóricos, porém não se mostraram dispersos e nem se 
ausentaram da aula. Os alunos da sala submetida à aula tradicional seguida pelo jogo apresentaram basicamente as mesmas reações dos outros tratamentos.

Durante a aula tradicional, houve maior centralização das atenções e do conteúdo pelo professor, sendo ele o personagem de destaque da aula. Na aplicação do jogo, apesar de se exigir pleno conhecimento do professor sobre o conteúdo, ele apresentou-se de forma mais discreta, sendo que o jogo foi o elemento central da aula.

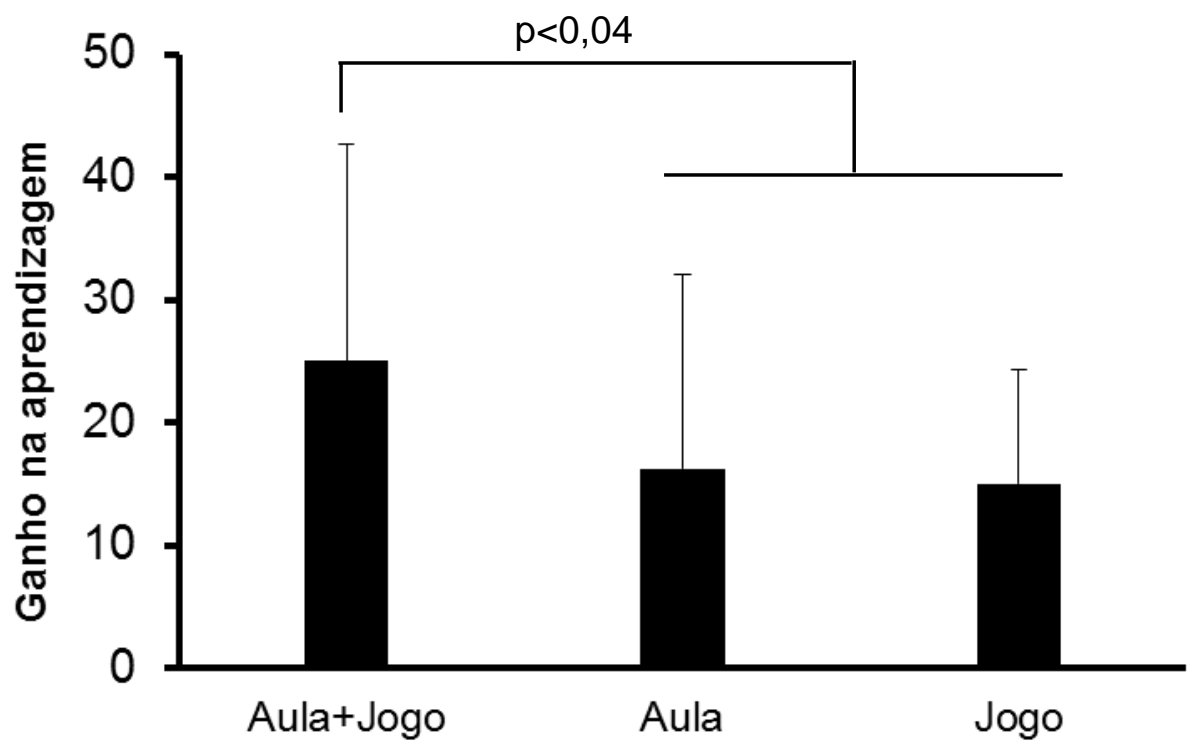

Figura 1. Ganho de aprendizagem média ( \pm desvio padrão) nos grupos submetidos a diferentes tratamentos: AULA+JOGO, AULA e JOGO.

Com relação à percepção dos discentes que participaram de ambas as atividades, 18\% preferiram a aula tradicional, qualificando-a como mais aprofundada, enquanto que $62 \%$ preferiram a aula com o uso exclusivo do jogo, alegando que aprender brincando possibilita maior atenção, além de aproximar os alunos e o professor. Também tiveram aqueles que defenderam o uso de ambas as metodologias, pelo fato de que uma complementa a outra. Estes compuseram $20 \%$ do grupo em análise. No que diz respeito ao processo participativo, $74 \%$ dos alunos afirmaram que foram mais estimulados e interagiram melhor com o conteúdo exposto na aula com o jogo. Muitos disseram que por meio da dinâmica aplicada puderam compartilhar seus conhecimentos com os demais colegas, e assim, puderam também contribuir no processo de ensino-aprendizagem, sentindo-se assim mais motivados.

$\mathrm{Na}$ descrição do cotidiano escolar, reclamações relacionadas ao uso excessivo da oralidade e a prática imódica da escrita nas aulas foram encontradas em $89 \%$ dos questionários. Nesses casos, as aulas foram consideradas desgastantes e pouco estimuladoras. As sugestões apresentadas pela turma para a melhoria do aprendizado incluíram a preparação de aulas mais atraentes e eficientes na facilitação do saber, o uso de brincadeiras, o desenvolvimento de aulas de campo, o uso de equipamento multimídia, além de mudança no comportamento do docente para que apresente mais disposição, alegria e interatividade. 


\section{DISCUSSÃO}

O presente estudo evidenciou, por meio de uma abordagem quase-experimental, a influência positiva da utilização de um jogo pedagógico no ensino-aprendizado de estudantes do Ensino Fundamental. Uma das críticas para delineamentos quase-experimentais refere-se ao fato de que os sujeitos submetidos aos tratamentos não são aleatoriamente designados e, portanto, os sujeitos que compõem um grupo submetido a um determinado tratamento podem diferir em outras variáveis o que, por sua vez, pode influenciar os resultados (SANTOS; GRECA, 2013). Nesse caso, os efeitos do tratamento e das variáveis não controladas se confundem e a avaliação da relação causal entre variáveis resposta e explanatória de interesse pode ser comprometida. Apesar dessas deficiências, típicas de delineamentos quase-experimentais, neste estudo, minimizamos os efeitos da variabilidade entre turmas, por meio da utilização do ganho de aprendizagem como variável resposta, ao invés do escore obtido pelos estudantes ao final das aulas. Dessa forma, independentemente do nível de conhecimento prévio, as turmas foram avaliadas com relação ao ganho de aprendizagem, tornando as turmas (tratamentos) avaliadas comparáveis.

As turmas submetidas aos três tratamentos apresentaram ganho de aprendizagem. Isso indica que as aulas, independente da metodologia utilizada, foram suficientes para proporcionar o aprendizado sobre o tema "biomas" por parte dos alunos. Entretanto, o desempenho dos alunos não foi similar entre os tratamentos. A turma submetida à combinação de aula tradicional e jogo mostrou maior ganho de aprendizado em relação às demais turmas. A partir desses resultados fica evidente que a associação de metodologias proporciona resultados mais favoráveis, sugerindo um efeito aditivo das diferentes metodologias. De acordo com Canto e Zacarias (2008) as atividades lúdicas servem de apoio ao educador e de incentivo aos estudantes, devendo ser utilizadas com o intuito de tornar o ensino atual mais completo e, não apenas de revolucioná-lo. Deve ser abandonada a ideia de que a brincadeira é incompatível com a aprendizagem, uma vez que o prazer, a diversão e o entretenimento derivados da atividade lúdica também são compatíveis com a aquisição de novos conhecimentos e habilidades (PATRIARCHA-GRACIOLLI; ZANON; SOUZA, 2008).

Ao avaliar o grau de conhecimento sobre biomas, o teste de aprendizagem aplicado neste estudo concentrou-se na avaliação da aprendizagem cognitiva, que é aquela que resulta no armazenamento organizado de informações do ser que aprende (GARRIS; AHLERS; DRISKELL, 2002). A contribuição de jogos educativos foi demonstrada em outros estudos, considerando não somente a aprendizagem cognitiva (WHITE, 1984), mas também a aprendizagem motora e afetiva (GOPHER; WEIL; BAREKET, 1994; WIEBE; MARTIN, 1994). Apesar de não ter sido avaliado, é evidente o potencial do modelo de jogo empregado neste estudo para a aprendizagem afetiva e motora. Com a aplicação do jogo em grupos que competem entre si, os estudantes são estimulados a desenvolverem outras habilidades que não somente a cognição, tais como os movimentos para manipulação das peças dos jogos, assim como habilidades emocionais que envolvem relacionamento interpessoal e habilidades para trabalho em grupo.

A avaliação qualitativa da percepção dos estudantes com relação à aplicação do jogo reforçou o potencial do uso dessa metodologia como estratégia de ensino. Durante a aula tradicional foi observado certo desinteresse por parte dos alunos, que demonstraram pouco entusiasmo e expectativa. Essa reação é esperada quando se utiliza a metodologia tradicional 
como único recurso, uma vez que se aborda somente uma pequena parte da aprendizagem, podendo causar vários conflitos, como a interferência do professor no raciocínio do discente, o desinteresse dos estudantes com o conteúdo que raramente tem ligação a sua realidade, a subordinação do educando e a formação de alunos mecânicos e sem criatividade (REIS et al., 2012). Por outro lado, na aula com o uso do jogo, os estudantes mostraram-se participantes, contentes, interessados e confiantes. Corroborando o estudo de Souza (2007), isso só ocorreu porque os recursos didáticos foram usados como auxilio na assimilação do conteúdo, uma vez que além de desenvolverem a criatividade e darem mais ênfase ao assunto abordado, ajudam o aluno a ampliar suas habilidades. Estes recursos deixam a aula mais alegre, dinâmica, motivadora e completa (CASTOLDI; POLINARSKI, 2009).

Entre as problemáticas que envolvem a educação no contexto atual, a motivação do educando é fundamental para o desenvolvimento do trabalho do educador. É função do professor e da escola apresentarem meios que proporcionem a motivação, oportunizando um ambiente democrático, criativo e propício ao desenvolvimento harmonioso dos alunos (BINI; PABIS, 2008). O uso de jogos demonstrou ser uma eficiente ferramenta motivacional, como relatado pelos próprios alunos. De fato, a dinâmica envolvida neste trabalho é compatível com o modelo apresentado por Garris, Ahlers e Driskell (2002) para explicar os benefícios da aplicação dos jogos para a aprendizagem. De acordo com esse modelo, a efetividade dos jogos depende da associação de aspectos relacionados com suas próprias características, tais como a capacidade para despertar a curiosidade dos jogadores, o desafio, assim como da qualidade da informação que é transmitida ao praticá-lo. A associação desses componentes em uma atividade lúdica que desperta a motivação e o interesse dos jogadores são condições favoráveis para o aprendizado.

Algumas queixas como a falta de participação e interesse pelas aulas, ausência no cumprimento das tarefas, conversas entre colegas, "passeio" pela sala durante as aulas, ignorando a presença do professor, podem indicar sinais da ausência motivacional (BINI; PABIS, 2008). Durante a realização da aula tradicional (expositiva) estes comportamentos foram observados entre os discentes, não sendo observados durante o desenvolvimento da aula com o uso do jogo, em que todos os comportamentos apresentados pelos alunos estavam diretamente ligados à metodologia empregada. Também foi observado que os alunos apresentaram grande aceitação ao uso de uma metodologia diferente da tradicional. De fato, $82 \%$ dos alunos que se envolveram com as duas metodologias afirmaram sentirem-se motivados e perceberam a aula como sendo mais atrativa com a aplicação dos jogos.

O jogo pedagógico permitiu um maior envolvimento entre a turma e o professor, diminuindo a distância entre eles. Essa aproximação influenciou de forma positiva a disciplina dos alunos, isto é, o professor obteve maior respeito e maior capacidade de organização da sala, resultando em uma aula prazerosa. Portanto, as atividades lúdicas agregadas ao cotidiano escolar qualificam-se como uma ferramenta eficaz no que diz respeito ao despertar do interesse, garantindo um maior envolvimento na relação emocional-afetiva professor/aluno e aluno/aluno, servindo como mecanismo facilitador da assimilação do saber.

Propostas como a tendência liberal progressista de Libâneo (1990) afirmam que é mais importante o processo da aquisição do saber do que o saber propriamente dito, ou seja, a compreensão e a absorção do conteúdo ministrado estão associadas ao método de ensino utilizado. Desta forma, aprender torna-se um exercício prazeroso de desenvolvimento do conhecimento em um ambiente estimulador. Neste sentido a proposta da aplicação de jogos 
pedagógicos, associados a outras metodologias, é uma importante ferramenta de incentivo tanto para os professores como para os alunos, caracterizando uma ligação entre o prazer e o saber.

Em resumo, o presente estudo apresentou por meio de uma abordagem experimental quantitativa, associada à avaliação qualitativa da percepção dos alunos, o potencial dos jogos pedagógicos para o ensino de ciências. Além de proporcionar maior aprendizagem quando associado à aula tradicional, os jogos motivam e tornam a aula mais atrativa. Ressalta-se ainda a importância da realização de estudos longitudinais, visando avaliar se os efeitos da aplicação dos jogos pedagógicos observados em curto prazo repercutem em longo prazo.

\section{CONCLUSÃO}

Foi possível constatar que, quando combinadas com metodologias tradicionais, as técnicas de ensino/aprendizagem lúdicas podem gerar resultados mais satisfatórios de aprendizagem. $\mathrm{O}$ uso dos jogos pedagógicos é eficiente como atividade complementar às aulas expositivas, pois possibilita a dinamização das aulas e permite uma maior compreensão e fixação dos conteúdos, servindo de auxílio na formação de uma metodologia mais completa e eficiente.

\section{REFERÊNCIAS}

1. ALMEIDA, P. N. Educação Lúdica: Técnicas e Jogos Pedagógicos. São Paulo: Editora Loyola, 2003.

2. BINI, L. R.; PABIS, N. Motivação ou interesse do aluno em sala de aula e a relação com atitudes consideradas indisciplinares. Revista Eletrônica Lato Sensu, Paraná, v.3, n.1, p. 1-19, 2008.

3. CANTO, A. R.; ZACARIAS, M. A. Utilização do Jogo Super Trunfo Árvores Brasileiras como Instrumento Facilitador no Ensino dos Biomas Brasileiros. Ciências \& Cognição, Bauru, v. 14, n. 1, p. 144-153, 2009.

4. CASTOLDI, R.; POLINARSKI, C. A. A Utilização de Recursos Didático-Pedagógicos na Motivação da Aprendizagem. In: I Simpósio Nacional de Ensino de Ciências e Tecnologia, Anais... Paraná: UTFPR, 2009. p. 684-692.

5. GARRIS, R.; Ahlers, R.; DRISKELL, J. E. Games, motivation, and learning: a research and practice model. Simulation \& Gaming, Oaks, vol. 33, n. 4, p. 441-467, 2002.

6. GOPHER, D.; WEIL, M.; BAREKET, T. Transfer of skill from a computer game trainer to flight. Human Factors, Santa Monica, vol. 36, n. 3, p. 387-405, 1994.

7. GRÜBEL, J, M; BEZ, M, R. Jogos Educativos. RENOTE. Revista Novas Tecnologias na Educação, v.2, n. 4, p. 1-7, 2006.

8. KNÜPPE, L. Motivação e desmotivação: desafio para as professoras do ensino fundamental. Educar em Revista, Curitiba, n. 27, p.277-290, 2006.

9. LIBÂNEO, J. C. Democratização da Escola Pública. São Paulo: Loyola, 1990.

10. MACEDO, L.; PETTY, A. L. S.; PASSOS, N. C. Os Jogos e o Lúdico na Aprendizagem Escolar. Porto Alegre: Artmed, 2005, 110p.

11. MEIRIEU, P. O cotidiano da escola e da sala de aula: o fazer e o compreender. Porto Alegre: 
Artmed Editora, 2005.

12. MINISTÉRIO DA EDUCAÇÃO (Secretaria de Educação Básica). Orientações curriculares para o ensino médio: Ciências da natureza, matemática e suas tecnologias. MEC: Brasília: 2006. 135 p.

13. PATRIARCHA-GRACIOLLI, S. R.; ZANON, A. M.; SOUZA, P. R. Jogo dos predadores: uma proposta lúdica para favorecer a aprendizagem em ensino de ciências e educação ambiental. Revista Eletrônica do Mestrado em Educação Ambiental, Rio Grande, v. 20, n. 1, p. 202-216, 2008.

14. PEDROSO, C. V. Jogos didáticos no ensino de biologia: uma proposta metodológica baseada em módulo didático. In: IX Congresso Nacional de Educação e III Encontro Sul Brasileiro de Psicopedagogia, Anais... Paraná: PUCPR, 2009. p. 3182-3190.

15. REIS, P. M. C. L. et al. Metodologias de Ensino Preferidas pelos Discentes dos Cursos Superiores do IF Sertão-PE - Campus Petrolina. In: VII Congresso Norte Nordeste de Pesquisa e Inovação, Anais... Palmas: IFTO, 2012. p. 1-7.

16. SANTOS, F. M. T.; Greca, I. M. Metodologias de pesquisa no ensino de ciências na América Latina: como pesquisamos na década de 2000. Ciência \& Educação, v. 19, n. 1, p. 15-33, 2013.

17. SilvA, A. M. T. B.; MetTRAU, M. B.; BARRETO, M. S. L. O lúdico no processo de ensinoaprendizagem das ciências. Revista Brasileira de Estudos Pedagógicos, Brasília, v. 88, n. 220, p. 445-458, 2007.

18. SOUZA, S. E. O. Uso de Recursos Didáticos no Ensino Escolar. In: I Encontro de Pesquisa em Educação, IV Jornada de Prática de Ensino, XIII Semana de Pedagogia da UEM: "Infância e Práticas Educativas", Anais... Maringá: UEM, 2007. p. 110-114.

19. WIEBE, J. H.; MARTIN, N. J. The impact of a computer-based adventure game on achievement and attitudes in geography. Journal of Computing in Childhood Education, Chesapeake, vol. 5, n. 1, p. 61-71, 1994. 